\title{
Evaluation of Clinical and Laboratory Prognostic Risk Factors in Organophosphate or Carbamate-Poisoned Pediatric Patients
}

\author{
(1) Mehmet Açıkgöz
}

Department of Pediatrics, Ondokuz Mayıs University Faculty of Medicine, Samsun, Turkey

\begin{abstract}
Aim: We aimed to determine the clinical and demographic features of pediatric patients monitored at our hospital after organophosphate or carbamate intoxication. Moreover, we aimed to determine the clinical and laboratory indicators that can affect the clinical severity scores and patients' prognosis.

Materials and Methods: We retrospectively analyzed 117 patients, aged less than 18 years and admitted to the pediatric emergency department for organophosphate or carbamate intoxication.

Results: The median age was 56 months (8-226 months), and the male-to-female ratio was 1.72 (74/43). The most frequent cause of intoxication was accidental ingestion (83.8\%), and the oral route was the most common (73.5\%). The Glasgow Coma Scale (GCS) score and serum pseudocholinesterase level were significantly low in the following groups: patients with a severe grade of intoxication, patients admitted to the intensive care unit, and patients with complications. However, lactate and glucose levels were significantly high in the previously mentioned patient groups $(\mathrm{p}<0.001)$. The mean range of red cell distribution width was significantly higher in patients admitted to the intensive care unit compared with those monitored in the emergency department $(p=0.029)$.

Conclusion: This study shows that GCS score and serum pseudocholinesterase, glucose, and lactate levels at baseline can be helpful in predicting the presence of a serious intoxication and aid in the prognosis of pediatric patients.
\end{abstract}

Keywords: Organophosphates, carbamates, poisoning, pseudocholinesterase, lactate, children

\section{Introduction}

Organophosphates and carbamates, commonly used as pesticides in agricultural fields and industry, are covalent inhibitors of the enzyme acetylcholinesterase (AChE). The easy accessibility of these compounds leads to frequent cases of accidental or suicidal ingestion, especially in developing countries (1,2). According to data from the World Health Organization, approximately 3 million cases of pesticide intoxication occur annually worldwide, and 220,000 of these result in death, though some series have described mortality as high as $25 \%(3,4)$. The few studies that have reported on childhood poisoning deaths have found mortality rates between $0 \%$ and $8.5 \%$ (1,5-8).
Intoxication may occur via inhalation, oral ingestion, and absorption through the skin $(1,9,10)$. Most of the intoxication cases due to ingestion of organophosphates can heal by supportive care and close monitoring. Life-threatening complications and death are rather rare. Many clinical and laboratory prognostic parameters to predict a serious clinical course and a poor prognosis in adulthood age groups have been investigated (11-13).

This study aimed to determine the clinical and demographic features of pediatric patients monitored after organophosphorus or carbamate intoxication in our hospital. We further aimed to determine the clinical and laboratory indicators that may be effective on the clinical severity scores and the prognoses of the patients. 


\section{Materials and Methods}

We retrospectively analyzed 117 cases who were younger than 18 years of age and were admitted to the pediatric emergency department for organophosphate or carbamate intoxication. The diagnosis of organophosphate or carbamate intoxication was established if any one of the following criteria were present: 1) self or family report of exposure to insecticides; 2 ) low serum pseudocholinesterase levels; 3 ) characteristic signs and findings of organophosphate or carbamate intoxication (sweating, vomiting, myosis, fasciculation, abdominal pain, hypotonia, bradycardia, diarrhea, hypotension, urinary incontinence); and 4) improvement in specific findings provided by atropine and oximes.

The following data for each of the cases were recorded: age, medical history, history of intoxication (ingestion time of organophosphates; cause and route of exposure), accompanying symptoms, clinical findings, and the Glasgow Coma Scale (GCS) score. We also recorded laboratory test results at baseline including: white blood cell count (WBC), hematocrit, hemoglobin, thrombocyte count, mean platelet volume (MPV), red blood cell distribution width (RDW), serum blood urea nitrogen, serum creatinine, serum aspartate aminotransferase (AST), serum alanine aminotransferase (ALT), glucose levels, sodium and potassium concentrations, lactate levels, arterial blood gas levels, and just the pseudocholinesterase levels at 0, 6, 12, 24, 48, and 72 hours. Additional data included electrocardiogram (ECG) findings, administered therapies, duration of the hospital stay at the hospital ward and intensive care unit, the need for endotracheal intubation and mechanical ventilation, and treatment outcomes.

The cases were grouped as patients with mild, moderate, and severe toxicity according to Dreisbach's classification (Appendix 1) (14).

\section{Statistical Analysis}

All parameters were analyzed with the Statistical Package for the Social Sciences (SPSS) software, version 21.0 (SPSS Inc., Chicago, IL, USA). Control of the normal distribution of data was made with Shapiro-Wilks tests. All categorical variables are represented

\begin{tabular}{|l|l|}
\hline $\begin{array}{l}\text { Appendix 1. Dreisbach's classification showing severity of } \\
\text { poisoning }\end{array}$ \\
\hline Grade & Symptoms \\
\hline Mild & Nausea, vomiting, diarrhoea, sweating \\
\hline Moderate & Lacrimation, salivation, miosis, fasciculation \\
\hline Severe & $\begin{array}{l}\text { Incontinence, apnoeic spells, acute respiratory } \\
\text { distress syndrome, areflexia, seizures, coma }\end{array}$ \\
\hline
\end{tabular}

as numbers and percentages, whereas numerical variables are displayed as mean \pm standard deviation and median (minimummaximum). The values of patients were analyzed with Mann-Whitney $U$ tests. A p-value of $<0.05$ was considered statistically significance. Receiver-operating characteristic curves for predicting the severity were generated from the data. Sensitivity and specificity were also calculated for glucose, GCS, lactate levels, RDW, and pseudocholinesterase levels.

\section{Results}

The median age of the cases was 56 months (8-226 months) and the male/female ratio was 1.72 (74/43). The most frequent causes of intoxication were accidental ingestion (83.8\%) and oral ingestion (73.5\%). Of all of the cases, $88.9 \%$ were exposed to organophosphorus or carbamate compounds in rural areas. The mean duration until admission to our hospital was $5.79 \pm 7.94$ hours (0.5-72 hours). However, $47.9 \%$ of the cases were admitted to the hospital within the first 4 hours. The most common treatment applied in the patients' homes was washing (19.7\%), while the most frequent intervention in the first admitted health facility was gastric lavage (59.8\%). The demographic and clinical characteristics of the patients are presented in Tables 1 and 2.

The most frequent complaints in the cases for admission to the emergency department were nausea and vomiting $(47.8 \%$ and $41 \%$, respectively), while the most commonly detected physical examination finding in the emergency department was myosis (17.1\%). According to evaluations of the cases based on states of consciousness, 94 (80.3\%), 11 (9.4\%), 5 (4.3\%), and 7 (6.0\%) were conscious, lethargic, in a stupor, and comatose, respectively. The complaints and findings of the patients are presented in Table 2.

According to patient evaluations in accordance with the Dreisbach's classification, $78.6 \%$ were in the group with mildmoderate grade intoxication. Respiratory failures, convulsions, and arrhythmias developed in 10 (8.5\%), 4 (3.4\%), and $3(2.5 \%)$ of the cases, respectively (Table 2 ).

The GCS score and levels of pseudocholinesterase were significantly lower in the following groups: in the patient group with severe grade intoxication, in cases admitted to the intensive care unit, and in those with complications. However, lactate and glucose levels were significantly higher in those patient groups $(p<0.001)$ (Tables 3 and 4).

Hyperglycemia was detected in $28(23.9 \%)$ cases, whereas hypoglycemia was not observed in any of the patients. Hyponatremia, hypopotassemia, acidosis, and high levels of AST and ALT were encountered in 36 (30.7\%), 15 (12.8\%), 41 (35\%), 4 (3.4\%), and 3 (2.6\%) of the patients, respectively. 


\begin{tabular}{|c|c|}
\hline \multicolumn{2}{|l|}{ Gender, n (\%) } \\
\hline Male & $74(63.2)$ \\
\hline Female & $43(37.8)$ \\
\hline \multicolumn{2}{|l|}{ Cause of poisoning, $\mathbf{n}(\%)$} \\
\hline Accidental & $98(83.8)$ \\
\hline Suicide & $19(16.2)$ \\
\hline \multicolumn{2}{|l|}{ Route of exposure, $n(\%)$} \\
\hline Ingestion & $86(73.5)$ \\
\hline Inhalation & $10(8.5)$ \\
\hline Skin & $5(4.3)$ \\
\hline Multiple & $16(13.7)$ \\
\hline \multicolumn{2}{|l|}{ Place of exposure, $n(\%)$} \\
\hline Rural & $104(88.9)$ \\
\hline Urban & $13(11.1)$ \\
\hline \multicolumn{2}{|c|}{$\begin{array}{l}\text { Duration between exposure and first medical intervention (hour), } \\
\mathrm{n}(\%)\end{array}$} \\
\hline $0-4$ hour & $56(47.9)$ \\
\hline 5-8 hour & 39 (33.3) \\
\hline$>8$ hour & $22(18.8)$ \\
\hline \multicolumn{2}{|l|}{ Pre-hospital applications, n (\%) } \\
\hline \multicolumn{2}{|l|}{ In home } \\
\hline Bathe & $23(19.7)$ \\
\hline Yoghurt feeding & $15(12.8)$ \\
\hline Drink of milk & $15(12.8)$ \\
\hline Induction of vomiting & $11(9.4)$ \\
\hline \multicolumn{2}{|l|}{ In hospital } \\
\hline Skin decontamination & $62(53.0)$ \\
\hline Gastric lavage & 70 (59.8) \\
\hline Activated charcoal & $51(43.5)$ \\
\hline Pralidoxime & $3(2.6)$ \\
\hline Atropine & $8(6.8)$ \\
\hline \multicolumn{2}{|l|}{ Treatment modalities in PEU, $\mathrm{n}(\%)$} \\
\hline Skin decontamination & $59(50.4)$ \\
\hline Gastric lavage & $59(50.4)$ \\
\hline Activated charcoal & $51(43.5)$ \\
\hline Both atropine and pralidoxime & $13(11.1)$ \\
\hline Atropine only & $2(1.7)$ \\
\hline Mechanical ventilation & $8(6.8)$ \\
\hline \multicolumn{2}{|l|}{ Observation time (median, min-max) } \\
\hline Outcomes, n (\%) & $24(5-2880)$ \\
\hline Observation in PEU & 95 (85.4) \\
\hline Admitted to PICU & $17(14.5)$ \\
\hline Out of the hospital at his own request & $5(4.2)$ \\
\hline Recovery with sequelae & $1(0.9)$ \\
\hline Mortality & $1(0.9)$ \\
\hline
\end{tabular}

\section{Table 2. Clinical findings}

Dreisbach's classification, $\mathbf{n}(\%)$

\begin{tabular}{|l|l}
\hline Mild-moderate & $92(78.6)$ \\
\hline High & $25(21.4)$
\end{tabular}

Glaskow Coma Score, n (\%)

\begin{tabular}{l|l}
\hline $\mathrm{GCS} \leq 8$ & $18(15.4)$ \\
\hline $\mathrm{GCS}(9-12)$ & $9(7.7)$ \\
\hline GCS (13-15) & $90(76.9)$
\end{tabular}

Complication, $\mathbf{n}(\%)$

\begin{tabular}{|l|l|}
\hline Respiratory failure & $10(8.5)$ \\
\hline Convulsion & $4(3.4)$ \\
\hline Aritmia & $3(2.5)$ \\
\hline Cardiac arrest & $2(1.7)$ \\
\hline Shmic pneumonia & $1(0.9)$ \\
\hline Parasthesia & $1(0.9)$ \\
\hline
\end{tabular}

Signs and symptoms, $\mathrm{n}(\%)$

\begin{tabular}{l|l}
\hline Vomiting & $56(47.9)$ \\
\hline Nausea & $48(41.0)$ \\
\hline Miosis & $20(17.1)$ \\
\hline Tachycardia & $13(11.1)$ \\
\hline Salivation & $12(10.3)$ \\
\hline Respiratory failure & $10(8.5)$ \\
\hline Urinary retention & $9(7.7)$ \\
\hline Headache & $7(6.0)$ \\
\hline Hypotension & $5(4.2)$ \\
\hline Fever & $5(4.2)$ \\
\hline Seizures & $4(3.4)$ \\
\hline Arrhythmia & $2(1.7)$ \\
\hline Hypothermia & $2(1.7)$ \\
\hline Paresthesia & $1(0.9)$ \\
\hline Bradycardia & $1(0.9)$ \\
\hline
\end{tabular}

Abnormal laboratory, $\mathrm{n}(\%)$

\begin{tabular}{l|l}
\hline $\mathrm{pH}$ & $41(35.0)$ \\
\hline Sodium & $35(29.9)$ \\
\hline Glucose & $28(23.9)$ \\
\hline Potassium & $15(12.8)$ \\
\hline AST & $4(3.4)$ \\
\hline ALT & $3(2.5)$ \\
\hline
\end{tabular}

ALT: Alanine aminotransferase, AST: Aspartate aminotransferase, n: Number 
Table 3. The comparison of poisoned patient's severity according to demographic and laboratory findings

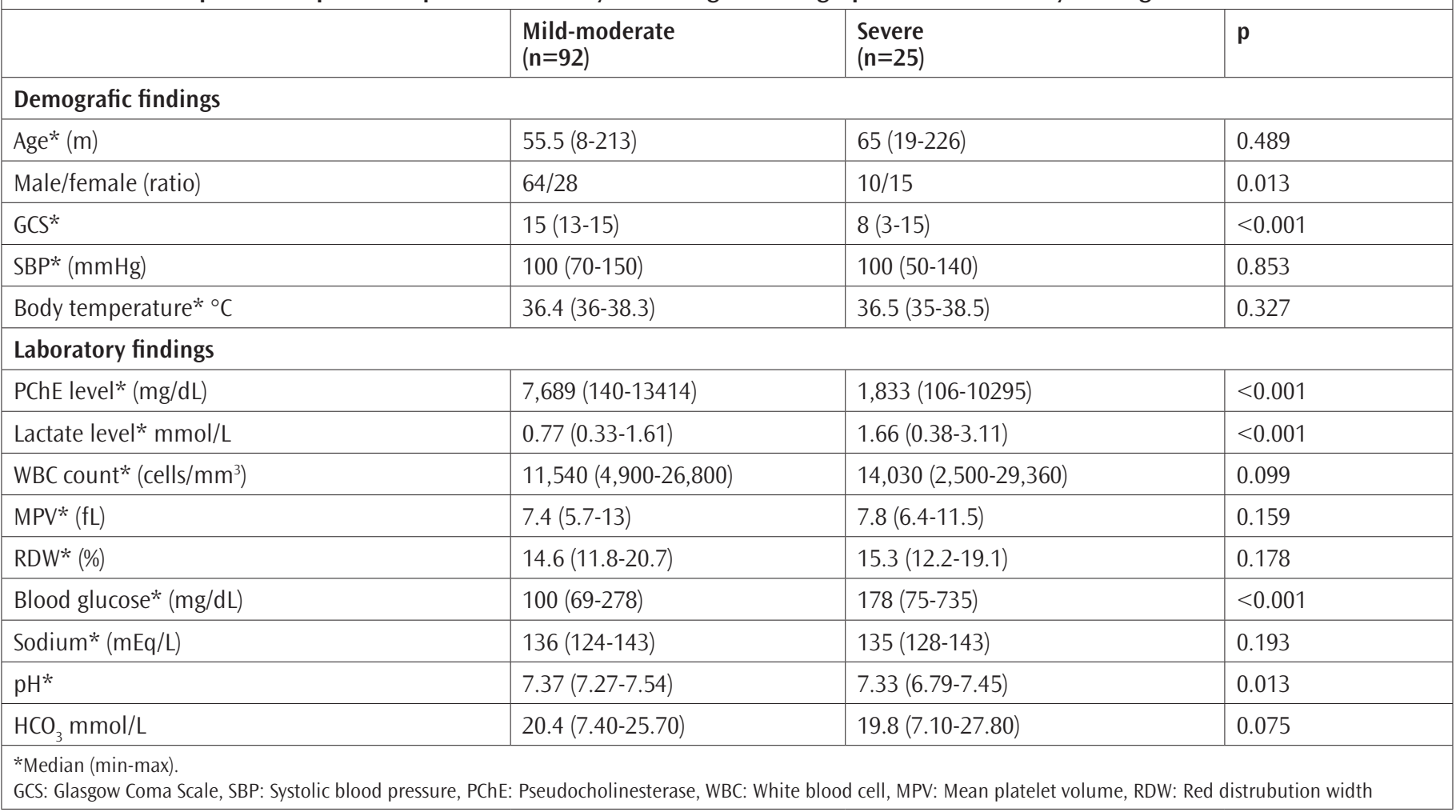

Table 4. The comparison of patients admitted to emergency service and intensive care unit according to demographic and laboratory findings

\begin{tabular}{|c|c|c|c|}
\hline & $\begin{array}{l}\text { Emergency service } \\
(n=100)\end{array}$ & $\begin{array}{l}\text { Intensive care unit } \\
(\mathrm{n}=17)\end{array}$ & $\mathbf{p}$ \\
\hline \multicolumn{4}{|l|}{ Demografic findings } \\
\hline Male/female (ratio) & $66 / 34$ & $8 / 9$ & 0.220 \\
\hline GCS* & $15(3-15)$ & $9(3-15)$ & $<0.001$ \\
\hline Body temperature* ${ }^{\circ} \mathrm{C}$ & $36.5(35-38.3)$ & $36.4(35-38.5)$ & 0.848 \\
\hline \multicolumn{4}{|l|}{ Laborotory findings } \\
\hline PChE level* (mg/dL) & 7,602 (130-13414) & 1,007 (106-4267) & $<0.001$ \\
\hline Lactate level* $\mathrm{mmol} / \mathrm{L}$ & $0.77(0.33-2.38)$ & $0.94(0.55-3.11)$ & 0.002 \\
\hline WBC Count* (cells/mm³) & $11,890(2,500-29,360)$ & $14,030(6,800-28,300)$ & 0.347 \\
\hline Blood Glucose* (mg/dL) & $102(69-278)$ & $196(75-735)$ & $<0.001$ \\
\hline Sodium* (mEq/L) & $136(124-143)$ & 135 (128-143) & 0.193 \\
\hline $\mathrm{pH}^{*}$ & $7.36(7.16-7.54)$ & $7.34(6.79-7.43)$ & 0.104 \\
\hline $\mathrm{HCO}_{3} \mathrm{mmol} / \mathrm{L}$ & $20.3(7.40-27.80)$ & $19.0(7.10-26.20)$ & 0.043 \\
\hline
\end{tabular}


There were no significant differences with respect to atrial blood pressure, fever, and levels of WBC, MPV, RDW, sodium, and $\mathrm{HCO}_{3}$ between the severe intoxication group and patients who were monitored as admitted in the intensive care unit or detected to suffer complication and the group with mild-moderate intoxication and patients who were monitored in the emergency department or without complications. The mean RDW levels were significantly higher in the patient group admitted to the intensive care unit compared with the group monitored in the emergency department $(p=0.029)$ (Table 4).

Whole body washing with plenty of soap and water after clothing removal was performed in the 59 patients suspected of becoming intoxicated through the skin. Gastric lavage was performed in the 59 (50.4\%) patients who experienced intoxication via the oral route and admitted to our hospital within the first hour, and 51 (43.5\%) patients were administered active charcoal. Atropine and pralidoxime sulphate were administered in 15 (12.8\%) and 23 (19.6\%) patients with muscarinic signs, respectively. Atropine was provided for $30.0 \pm 70.9$ hours and the total dose range was 0.2 $25 \mathrm{mg}$. Pralidoxime sulphate was provided for $26.2 \pm 72.6$ hours with a total dose range of 25-175 mg.

All of the patients were monitored as admitted. Intensive care unit admissions comprised $14.6 \%$ of the cases. The median admission duration of the patients in the pediatric intensive care unit and hospital were 24 and 72 hours, respectively. Complications developed in 21 (17.9\%) patients. Cardiopulmonary arrest developed in two $(1.7 \%)$ cases and one $(0.9 \%)$ of those patients died.

\section{Discussion}

Organophosphates and carbamates are commonly used worldwide. Intoxication caused by ingestion of these compounds due to ineffective regulatory control of their sale and easy availability is an important community health issue, especially in developing countries (2).

Organophosphate compounds may cause intoxication via several routes including transdermal, inhalation, transmucosal, and the gastrointestinal system (2). Studies conducted on childhood age groups have reported intoxication rates via oral ingestion and the respiratory route as $61-88.4 \%(2,7,15)$ and $11.5 \%$, respectively (16). In our study, rates of intoxication via oral ingestion and the respiratory tract were $72.6 \%$ and $8.8 \%$, respectively. The intoxication rate via multiple pathways was $13.7 \%$ in our study.

As an interesting feature of our study, one case was intoxicated via a self-intramuscular injection. A $5 \times 5-\mathrm{cm}$ scar formation secondary to the injection was present on the arm.
The frequent findings due to muscarinic receptor stimulation are myosis, bradycardia, bronchospasms, bronchorrhea, increased salivation, lacrimation, nasal discharge, sweating, vomiting, diarrhea, and urinary incontinence (2). Zwiener and Ginsburg (6) reported in their retrospective study on 37 children aged 1 month to 11 years that the most common findings were myosis, salivation, decreased muscular strength, and lethargy, while tachycardia developed in $49 \%$ of patients. The most frequent findings of another study were diarrhea, vomiting, and myosis with rates of $100 \%, 96 \%$, and $89 \%$, respectively. Dippenaar et al. (15) have determined the most frequent signs as pin-point pupils in $78 \%$ of patients and excessive increases in secretions. In our study, the most common findings were vomiting, nausea, and myosis in 56 (47.9\%), 48 (41\%), and 20 (17.1\%) cases, respectively.

Many clinical and laboratory indicators such as the GCS score, systolic blood pressure, body mass index, Acute Physiology and Chronic Health Enquiry (APACHE) II score, serum cholinesterase level, amylase level, total leukocyte count, RDW, C-reactive protein, creatine phosphokinase, blood $\mathrm{pH}$, and prolonged QT on ECG have been tested to predict clinical courses in adult cases with acute organophosphate intoxication (11-13).

Studies have demonstrated that GCS scores are effective in predicting potential outcomes in organophosphorus intoxication (17). Bilgin et al. (18) compared the effectiveness of GCS, APACHE II, and the Simplified Acute Physiology Score (SAPS) II in predicting the mortality risk in patients with organophosphorus intoxication and reported that these three scoring systems provided similar outcomes. However, they determined that the GCS was more easily applicable and superior to other scoring systems since it does not require laboratory and complicated physiological parameters (19). Grmec et al.'s study (20) reported that GCS is a predictive indicator in estimating respiratory failure and mortality rate. Our findings were similar to those in the literature with regard to the fact that GCS can be used as a prognostic factor in predicting serious intoxication, development of complications, and the need for treatment in the intensive care unit.

Previous reports suggest that symptoms and findings of the respiratory system (bronchorrhea, bronchospasm, and weakened respiratory muscles) and central nervous system (an altered state of consciousness and seizures) have an important place in predicting mortality rates $(2,21)$. The essential determinants of mortality are respiratory failure and tissue hypoxia as the common result of involvement of both systems (2,19-21).

Many controversial studies on the relationship between the severity of intoxication and plasma AChE levels have been reported (22). There are many studies that have indicated there is no association between patients' clinical conditions at 
baseline and enzyme cholinesterase levels in organophosphate intoxications (1-2,15). Chen et al. (23) have reported that the absence of an elevation in AChE levels within 48 hours after treatment for organophosphate intoxication is associated with a high mortality rate. Manu et al. (24) have reported in their study on patients followed-up after organophosphate intoxication that serial measurements of serum AChE levels may be helpful in predicting the duration of mechanical ventilation, the duration of stay in the intensive care unit, and the prognosis. The outcomes of our study make us consider that the serum pseudocholinesterase level at baseline can be used as an indicator in predicting serious intoxications and treatment needs in the intensive care unit in pediatric patients.

Lactate is a byproduct of anaerobic metabolism and is accepted as an indicator of tissue hypoxia (25). It has been emphasized that serum lactate levels may be helpful as a predictive indicator. Trzeciak et al. (26) found that in a study of 100 patients that lactate levels over $4 \mathrm{mmol} / \mathrm{L}$ are highly specific in predicting mortality. Shapiro et al. (27) have reported that moderate and high-grade elevations in lactate levels lead to 2.2-fold and 7.1fold increases inmortality risk, respectively. In the current study, we found that serum lactate levels were effective in predicting the need for treatment in the intensive care unit, the development of complications, and serious intoxication findings in the patients. Also, the baseline lactate level of the patient who became exitus was $3.1 \mathrm{mmol} / \mathrm{L}$ in our study.

Serum glucose levels of the patients with organophosphorus intoxication have been investigated in various studies (28). It has been considered that hyperglycemia develops due to catecholamines secreted from the adrenal medulla (29-31). It has also been reported that there is a relationship between the severity of intoxication and serum glucose levels, and that glucose levels of the exitus cases were higher than those of survivors (2931). Floris Levy-Khademi et al. (5) declared a median glucose level of $130.5 \mathrm{mg} / \mathrm{dL}$ in their retrospective study of 31 children who were between 0.8 years and 12 years of age. Lifshitz et al. (16) have noted an increase in serum glucose levels $(155-280 \mathrm{mg} /$ $\mathrm{dL}$ ) in 23 of 26 cases. In our study, we found that serum glucose levels were significantly increased in those patients who were admitted to the intensive care unit and revealed findings of serious intoxication.

RDW is a hematological index that indicates varying size distributions of erythrocytes (32). In the studies conducted in recent years, high RDW levels have been shown to be associated with poor prognoses in various pathological conditions including heart failure, acute coronary syndrome, pulmonary embolism, and pancreatitis (33-35). The action mechanisms for elevated RDW levels have not been identified yet. However, it has been reported that a deformation of erythrocyte membranes due to acute or chronic inflammation may occur (35). Similarly, acute inflammation and oxidative stress, which are observed in organophosphate intoxication, may cause changes in the size and structure of circulating erythrocytes (36). A clinical trial found that RDW levels do not change in the patients with intoxication due to ingestion of low doses of organophosphates (37). Another study reported that RDW levels are an easy-to-use and valuable parameter in predicting the prognosis of patients poisoned with organophosphates (36). In our study, the mean RDW levels were significantly higher in the patient group who needed intensive care unit treatment compared to those who did not need this treatment.

Intoxication due to the ingestion of organophosphorus or carbamate compounds are serious situations that require early diagnoses and rapid treatments. The accepted treatment protocol involves decontamination, prevention of absorption, general supportive treatment, and pharmacological therapy $(1,3)$. Early detection of respiratory failure, early intubation, and mechanical ventilation are life-saving factors. El-Naggar et al. (2) have reported that they performed gastric lavage in 39 (83\%) cases while they used activated charcoal in all of the children who were intoxicated via the oral route. Lifshitz et al. (7) have reported that gastric lavage and activated charcoal were used in all of the children intoxicated via the oral route. In our study, 59 (51.8\%) cases were washed, and gastric lavage and activated charcoal were provided in 59 (50.4\%) and 51 (43.5\%) cases of the 85 patients poisoned via the oral route, respectively.

Atropine is a competitive antagonist of the muscarinic acetylcholine receptors in the central and peripheral nervous systems. High doses of atropine may be needed depending upon the severity of the clinical status. The maximum dose within a 24-hour period is $10-12 \mathrm{mg}(2,3)$. Pralidoxime is the most commonly used oxime worldwide and shows its effect by activating the enzyme cholinesterase on all the muscarinic and nicotinic receptors, which are under cholinergic effect and in the central nervous system $(2,3)$. Dippenaar and Diedericks (15) have declared that they administered only atropine in $48 \%$ of cases, whereas they used both atropine together with a single dose of obidoxime in $39 \%$ of cases. El-Naggar et al. (2) have stated that they administered only atropine in $47.4 \%$ of cases, however, they used both atropine and a single dose of obidoxime in $59.7 \%$ of cases. In our study, atropine and pralidoxime were administered in $15(13.2 \%)$ and 23 (20.2\%) cases, respectively.

Only atropine was administered in two cases, whereas only pralidoxime was administered in 10 cases. Atropine and pralidoxime were administered together in 13 cases. 
El-Naggar et al. (2) have detected that complications developed in $36 \%$ of cases. They reported the development of aspiration pneumonia, convulsions, and septic shock in $10.6 \%, 10.6 \%$, and $2 \%$ of patients, respectively. Lifshitz et al. (7) have declared that pulmonary edema developed in $11.5 \%$ of patients. Dippenaar and Diedericks (15) reported that convulsions developed in $4.3 \%$ of patients. It has been detected in studies conducted on childhood age groups that the rate of requiring mechanical ventilation was $5.7-17.3 \%(2,7,15)$. In our study, the complication rate was $17.9 \%$. The most frequent complications were compromised respiration, convulsions, and arrhythmias. Mechanical ventilation was needed in $10(8.5 \%)$ cases.

Mortality rates of $1.9 \%, 4.3 \%$, and $8.5 \%$ were reported in studies that were conducted in the childhood age groups $(2,7,15)$. In our study, one (0.9\%) patient was discharged with a sequela and one $(0.9 \%)$ patient became exitus while the other patients completely recovered.

The main limitation of our study as one of the largest pediatric case series was that it had a retrospective study design and only pseudocholinesterase levels of the patients were tested.

\section{Conclusion}

The outcomes of our study helped us to conclude that the GCS score and serum AChE, serum glucose, and serum lactate levels at baseline can be helpful in predicting the presence of a serious intoxication and aid in the prognosis in pediatric cases. Thus, there is a need for further prospective studies to be conducted on larger case series.

\section{Ethics}

\section{Ethics Committee Approval: Retrospective study}

\section{Informed Consent: Retrospective study}

Financial Disclosure: The author declared that this study has received no financial support.

\section{References}

1. Weissmann-Brenner A, Friedman LM, David A, Vidan A, Hourvitz A. Organophosphate poisoning: a multihospital survey. Isr Med Assoc. J 2002; 4:573-6.

2. El-Naggar Ael-R, Abdalla MS, El-Sebaey AS, Badawy SM. Clinical findings and cholinesterase levels in children of organophosphates and carbamates poisoning. Eur J Pediatr. 2009;168:951-6.

3. Singh UK, Layland FC, Prasad R, et al. Insecticide Poisoning. In: Poisoning in children. 4th ed. New Delhi: Jaypee Brothers Medical Publishers. 2013. s. $106-26$

4. Abdel Rasoul GM, Abou Salem ME, Mechael AA, Hendy OM, Rohlman DS, Ismail AA. Effects of occupational pesticide exposure on children applying pesticides. Neurotoxicology. 2008;29:833-8.
5. Levy-Khademi F, Tenenbaum AN, Wexler ID, Amitai Y. Unintentional organophosphate intoxication in children. Pediatr Emerg Care. 2007;23:7168.

6. Zwiener RJ, Ginsburg CM. Organophosphate and carbamate poisoning in infants and children. Pediatrics. 1988;81:121-6.

7. Lifshitz M, Shahak E, Sofer S. Carbamate and organophosphate poisoning in young children. Pediatr Emerg Care. 1999;15:102-3.

8. Sofer S, Tal A, Shahak E. Carbamate and organophosphate poisoning in early childhood. Pediatr Emerg Care. 1989;5:222-5.

9. Colović MB, Krstić DZ, Lazarević-Pašti TD, Bondžić AM, Vasić VM. Acetylcholinesterase inhibitors: pharmacology and toxicology. Curr Neuropharmacol. 2013;11:315-35.

10. Eddleston M, Buckley NA, Eyer P, Dawson AH. Management of acute organophosphorus pesticide poisoning. Lancet. 2008;371:597-607.

11. Lee DH, Jung KY, Choi YH, Cheon YJ. Body mass index as a prognostic factor in organophosphate-poisoned patients. Am J Emerg Med. 2014;32:693-6.

12. Muley A, Shah C, Lakhani J, Bapna M, Mehta J. To identify morbidity and mortality predictors in acute organophosphate poisoning. Indian J Crit Care Med. 2014;18:297-300.

13. Senthilkumaran S, David SS, Menezes RG, Thirumalaikolundusubramanian P. C-reactive protein value in organophosphate-poisoned patients - Promises and pitfalls. Clin Toxicol (Phila). 2013;51:121.

14. Dreisbach RH. Handbook of poisoning. 11th ed. California: Lange Medical Publications; Cholinesterase inhibitor pesticides; 1983.s.106-14.

15. Dippenaar R, Diedericks RJ. Paediatric organophosphate poisoning--a rural hospital experience. S Afr Med J. 2005;95:678-81.

16. Lifshitz M, Rotenberg M, Sofer S, Tamiri T, Shahak E, Almog S. Carbamate poisoning and oxime treatment in children: a clinical and laboratory study. Pediatrics. 1994;93:652-5.

17. Cander B, Dur A, Yildiz M, Koyuncu F, Girisgin AS, Gul M, et al. The prognostic value of the Glasgow coma scale, serum acetylcholinesterase and leukocyte levels in acute organophosphorus poisoning. Ann Saudi Med. 2011;31:163-6.

18. Bilgin TE, Camdeviren H, Yapici D, Doruk N, Altunkan Z, Oral U. The comparison of the efficacy of scoring systems in organophosphate poisoning. Toxicol Ind Health. 2005;21:141-6.

19. Coskun R, Gundogan K, Sezgin GC, Topaloglu US, Hebbar G, Guven M, et al. A retrospective review of intensive care management of organophosphate insecticide poisoning: Single center experience. Niger | Clin Pract. 2015; 18:644-50.

20. Grmec S, Mally S, Klemen P. Glasgow Coma Scale score and QTc interval in the prognosis of organophosphate poisoning. Acad Emerg Med. 2004;11:925-30.

21. Stone CK, Drigalla D, Humphries RL, Stephan M. In: Organophosphate \&Carbamate Insecticides. Current Diagnosis and Treatment: Pediatric Emergency Medicine. New York: McGraw Hill; 2015. s. 656-7.

22. Aygun D. Diagnosis in an acute organophosphate poisoning: report of three interesting cases and review of the literature. Eur J Emerg Med. 2004;11:55-8.

23. Chen HY, Wang WW, Chaou CH, Lin CC. Prognostic value of serial serum cholinesterase activities in organophosphate poisoned patients. Am J Emerg Med. 2009;27:1034-9.

24. Manu MS, Prashant V, Akila P, Suma MN, Basavanagowdappa H. A retrospective analysis of serial measurement of serum cholinesterase in acute poisoning with organophosphate compounds. Toxicol Int. 2012;19:255-9.

25. Husain FA, Martin MJ, Mullenix PS, Steele SR, Elliott DC. Serum lactate and base deficit as predictors of mortality and morbidity. Am J Surg. 2003;185:485-91.

26. Trzeciak S, Dellinger RP, Chansky ME, Arnold RC, Schorr C, Milcarek B, et al. Serum lactate as a predictor of mortality in patients with infection. Intensive Care Med. 2007:33:970-7. 
27. Shapiro NI, Howell MD, Talmor D, Nathanson LA, Libson A, Wolfe RE, et al. Serum lactate as a predictor of mortality in emergency department patients with infection. Ann Emerg Med. 2005;45:524-8.

28. Gündüz E, Dursun R, Icer M, Zengin Y, Güllü MN, Durgun HM, et al. Factors affecting mortality in patients with organophosphate poisoning. J Pak Med Assoc. 2015;65:967-72.

29. Sungur M, Güven M. Intensive care management of organophosphate insecticide poisoning. Crit Care. 2001;5:211-5.

30. Yurumez Y, Durukan P, Yavuz Y, Ikizceli I, Avsarogullari L, Ozkan S, et al. Acute organophosphate poisoning in university hospital emergency room patients. Intern Med. 2007;46:965-9.

31. Panda S, Nanda R, Mangaraj M, Rathod PK, Mishra PK. Glycemic Status in Organophosphorus Poisoning. J Nepal Health Res Counc. 2015;13:214-9.

32. Clarke K, Sagunarthy R, Kansal S. RDW as an additional marker in inflammatory bowel disease/undifferentiated colitis. Dig Dis Sci. 2008;53:2521-3.
33. Kaya A, Isik T, Kaya Y, Enginyurt O, Gunaydin ZY, İscanli MD, et al. Relationship between red cell distribution width and stroke in patients with stable chronic heart failure: a propensity score matching analysis. Clin Appl Thromb Hemost. 2015;21:160-5.

34. Montagnana M, Cervellin G, Meschi T, Lippi G. The role of red blood cell distribution width in cardiovascular and thrombotic disorders. Clin Chem Lab Med. 2011;50:635-41.

35. Şenol K, Saylam B, Kocaay F, Tez M. Red cell distribution width as a predictor of mortality in acute pancreatitis. Am J Emerg Med. 2013;31:687-9.

36. Dündar ZD, Köylü R, Ergin M, Günaydın YK, Özer R, Cander B. Prognostic Value of Red Cell Distribution Width in Patients with Organophosphate Poisoning. JAEM. 2015;14:65-9.

37. Al-Sarar AS, Abo Bakr Y, Al-Erimah GS, Hussein HI, Bayoumi AE. Hematological and biochemical alterations in occupationally pesticides-exposed workers of Riyadh Municipality, Kingdom of Saudi Arabia. Res J Environ Toxicol. 2009;3:179-85 